\title{
HBx represses RIZ1 expression by DNA methyltransferase 1 involvement in decreased miR-152 in hepatocellular carcinoma
}

\author{
ZHUJIANG ZHAO ${ }^{1}$, YING HU ${ }^{1}$, XIAOHUI SHEN ${ }^{1}$, YINGBIN LAO ${ }^{1}$, LIHUA ZHANG $^{2}$, XUEMEI QIU ${ }^{1}$, \\ JIAOJIAO HU ${ }^{1}$, PIHAI GONG ${ }^{1}$, HE CUI $^{3}$, SEN LU ${ }^{3}$, YING ZHENG ${ }^{1}$, MENGHAN ZHOU $^{1}$ and HONG FAN ${ }^{1}$ \\ ${ }^{1}$ Department of Medical Genetics and Developmental Biology, Medical School of Southeast University \\ and The Key Laboratory of Developmental Genes and Human Diseases, Ministry of Education, \\ Southeast University; ${ }^{2}$ Department of Pathology, Southeast University, Zhongda Hospital; \\ ${ }^{3}$ The First Affiliated Hospital of Nanjing Medical University, Nanjing, Jiangsu, P.R. China
}

Received September 2, 2016; Accepted January 26, 2017

DOI: $10.3892 /$ or.2017.5518

\begin{abstract}
Hepatitis B virus (HBV) is mainly suspected to promote hepatocellular carcinoma (HCC) development by epigenetic alteration. The HBV X protein (HBx) plays a key role in the molecular pathogenesis of HBV-related HCC. However, the mechanism of HBx-mediated hepatocarcinogenesis remains to be elucidated. RIZ1 gene, a candidate HCC suppressor gene, is frequently found to be hypermethylated and downregulated in HCC. In the present study, we show that the expression of RIZ1 was downregulated in $65 \%$ HCC tissues. Decreased expression of RIZ1 was restored by 5 '-Aza in MHCC-97H HCC cell lines. HBx recombinant transfection increased DNMT1 expression level and suppressed RIZ1 expression. Moreover, knockdown of DNMT1 by siRNA restored RIZ1 expression in HCC cell SMMC-7721 and reduced methylated $\mathrm{CpG}$ sites of RIZ1. ChIP results showed that DNMT1 protein could bind to RIZ1 promoter, and this interaction was further enhanced with the transfected HBX recombinant. Moreover, miR-152 was decreased and involved in upregulation of DNMT1 in HBx transfected cells, at least partly, contributed to the epigenetic inactivation of RIZ1.
\end{abstract}

Correspondence to: Professor Hong Fan, Department of Medical Genetics and Developmental Biology, Medical School of Southeast University, The Key Laboratory of Developmental Genes and Human Diseases, Ministry of Education, 87 Dingjiaqiao Road, Nanjing, Jiangsu 210009, P.R. China

E-mail: fanh@seu.edu.cn

Abbreviations: $\mathrm{HCC}$, hepatocellular carcinoma; HBV, hepatitis B virus; HBx, hepatitis $\mathrm{B}$ virus $\mathrm{x}$ protein; miRNA, microRNA; DNMTs, DNA methyltransferases; MSP, methylation-specific PCR; qPCR, quantitative real time PCR; siRNA, small interfering RNA; TSG, tumor suppressor gene. RIZ1, retinoblastoma proteininteracting zinc finger gene 1

Key words: hepatocellular carcinoma, hepatitis B virus $\mathrm{X}$ protein, RIZ1, miR-152
Taken together, our data found that HBx repressed RIZ1 expression via DNMT1, which offered a new mechanism of RIZ1 inactivation in HCC, except for the widely known DNA methylation. These results enriched the epigenetic mechanism by which HBx contributes to pathogenesis of HBV-HCC.

\section{Introduction}

Hepatocellular carcinoma (HCC) arises from hepatocytes and ranks as the fifth most common cancer in men and the seventh in woman (1). From etiological factors, chronic HBV infection currently accounts for more than one-half of HCC cases worldwide, especially in China. The risk of developing HCC is increased by 10 to 100 -fold for HBV carries $(2,3)$. Among HBV proteins, $\mathrm{HBx}$ is a multifunctional regulator and play a crucial role in heptocellular carcinogenesis, including in cell cycle regulation, signaling pathway, and genomic DNA instability. HBx also plays a role in epigenetic modification, such as DNA methylation and histone modification $(4,5)$. HBx upregulated DNA methyltransferases (DNMTs) responsive for DNA methylation leading to inactivation of tumor suppressor genes (TSGs) (6-8). The current evidence demonstrates that $\mathrm{HBx}$ can affect regulatory non-coding RNAs, including microRNAs and long ncRNAs $(9,10)$. We also reported that HBx upregulated miR-21 and promote the proliferation of hepatoma cells (11).

Our study groups analyzed the different expression genes between the L02-HBx and L02-Vector control cells using microarray analysis, and the result showed HBx upregulated 456 genes and downregulated 843 genes. Among them, RIZ1, encoding a member of PRDM protein family, was found downregulation by more than 5-fold. RIZ1 (PRDM2) was first isolated by screening for proteins. RIZ1 (PRDM2) was named retinoblastoma protein-interacting Zinc finger gene in a screen for proteins binding the retinoblastoma $(\mathrm{Rb})$ protein (12). Dysregulation of RIZ1, is associated with cancer, and act as a tumor suppressor that can induce cell growth arrest and apoptosis, and are inactivated in various human cancers (13-15). Inactivation of the RIZ1 (PRDM2) gene by promoter hypermethylation has been reported in liver and gastric carcinomas (15-19). To investigate the association of 
RIZ with HCC, we measured the expression level of RIZ1 by immunohistochemistry in protein level and qRT-PCR in transcript level in HCC cases. There was no significant correlation between RIZ1 protein level and patient age, gender or tumor size. However, lower protein expression level of RIZ1 was obvious in tumor tissues compared to peri-carcinoma tissues. To elucidate the mechanism on downregulation of RIZ1 in $\mathrm{HCC}$, we reasoned that it should be regulated by some epigenetic regulation. Earlier studies indicated that $\mathrm{HBx}$ attributed to the downregulation of gene and non-coding RNA transcription through increasing DNMT activity with the upregulation of DNMT1, or/and DNMT3A, or/and DNMT3B (5).

\section{Materials and methods}

HCC patient samples. All of the HCC tumor tissues, together with paired non-tumor liver tissues $(5 \mathrm{~cm}$ away from tumor boarder) from $68 \mathrm{HCC}$ patients were obtained from the First Affiliated Hospital of Nanjing Medical University. All the samples were collected with written consent provided by patients. This study was performed with ethical consent granted from the medical ethics committee of the Medical School of Southeast University.

Cell culture. HCC-derived cell lines, SMMC-7721, MHCC-97H, chang liver, Huh7, QGY-7703, HepG2.2.15), paracancerous cell line QSG-7701, and immortalized human normal hepatocyte cell line L02 were obtained from TCC Cell Bank (Shanghai, China). All the cell lines were cultured with RPMI-1640 (Gibco-BRL, Gaithersburg, MD, USA) supplemented with $10 \%$ fetal bovine serum (Gibco-BRL) in $5 \% \mathrm{CO}_{2}$ humidified chamber at $37^{\circ} \mathrm{C}$.

Immunohistochemical analysis. Immunohistochemistry (IHC) was used to detect RIZ1 protein expression in HCC 68 tumor and adjacent non-tumor tissues, and the IHC were performed as previously described (20). Briefly, paraffin embedded tissue specimens from all 68 patients were incubated with specific primary antibodies against RIZ1 (Abcam, ab3790) overnight at $4^{\circ} \mathrm{C}$ after antigen retrieval, followed by incubation with biotinylated secondary antibodies anti-goat IgG. The sections were then treated with Vectastain Elite ABC reagent (Vector Laboratories, Mountain View, CA, USA). All sections were counterstained with haematoxylin. Images were captured using Nikon Eclipse TE2000-S microscope system (Nikon, Melville, NY, USA).

Reverse transcription polymerase chain reaction (RT-PCR) and real-time quantitative $R T-P C R(q R T-P C R)$. Total RNA was isolated using TRIzol reagent (Invitrogen, Carlsbad, CA, USA). cDNA was synthesized from $1 \mu \mathrm{g}$ of total RNA using Oligo(dT) as primers and reverse-transcribed according to the kit's instructions (Takara, Dalian, China). The qPCR was carried out using the SYBR Premix Ex Taq (Takara) according to the manufacturer's protocol by StepOne Plus system (Applied Biosystems, Foster City, CA, USA). The real-time PCR reactions were performed in triplicate and $\beta$-actin was used as the internal control. The relative expression was evaluated by the comparative CT method ( $2^{-\Delta \Delta \mathrm{Ct}}$ method). The primer sequences of each gene are shown in Table I.
Western blot analysis. Cells $\left(5 \times 10^{6}\right)$ were harvested and lysed in $0.2 \mathrm{ml}$ of ice-cold lysis buffer $[10 \mathrm{mmol} / 1$ Tris- $\mathrm{HCl}$ (pH 8.0), containing $150 \mathrm{mmol} / 1 \mathrm{NaCl}, 1 \mathrm{mmol} / \mathrm{l}$ phenylmethylsulfonyl fluoride, and $1 \%$ Triton X-100]. An equal amount of cellular proteins were separated by sodium dodecyl sulfate-polyacrylamide gel electrophoresis (SDS-PAGE) on 10 or $12 \%$ resolving gels. Proteins were electrophoretically transferred onto nitrocellulose membranes and incubated overnight at 4 in block buffer [ $5 \%$ non-fat milk in Tris-Base Tween-20 (TBST)]. Membranes were incubated for $1 \mathrm{~h}$ at room temperature with specific monoclonal antibodies for RIZ1 (1:1000, Sigma), for His tag (Fusion expression with HBx) (1:1000, Cell Signaling Technology) for DNMT1 (1:1000, Santa) and $\beta$-actin (1:8000, Sigma) antibodies followed by six 5-min washes with TBST. After washing, the membrane was incubated with horseradish peroxidaseconjugated secondary antibodies (1:80000, Sigma), and the immune complexes were detected with enhanced chemiluminescence (Pierce). $\beta$-actin protein levels were used as a control to ensure equal protein loading. Each experiment was repeated at least 3 times. The intensity ratios of bands were determined and calculated by Gel-Pro Analyzer 3.0.

Transfection. The miR-152 mimics and specific siRNAs targeting DNMT1 and the control scrambled sequence siRNA were synthesized by GenePharma (Shanghai, China), the sequences are listed in Table I. The cells were transfected with mimics and siRNA using the Lipofectamine 2000 kit (Invitrogen). After 48 or $72 \mathrm{~h}$, cells were harvested for analysis. SMMC-7721 cells were transiently transfected with the pcDNA4/TO-HBx1, pcDNA4/TO-HBx2 construct, or the control pcDNA4/TO using the FuGene HD transfection reagent (Roche, Mannheim, Germany). The transfection process followed the manufacturer's protocol. L02-HBx no. 1 (L02-HBx \#1) and L02-HBx no. 8 (L02-HBx \#8) were the two isolated HBx transfectants (gifts from Dr Xin-Yuan Guan, The University of Hong Kong).

Methylation-specific PCR (MSP) and treatment of 5'-Aza-dC. Genomic DNA was extracted from the cells using the phenolchloroform method followed by methylation-specific PCR were performed as described previously (1). Modified DNA from L02-Vector, L02-HBx \#1, L02-HBx \#8, 7721-Control and 7721-si-DNMT1 cells was amplified to determine the methylation status of the promoter region of gene by MSP. The primers used for amplifying methylated and unmethylated RIZ1 are listed in Table I. Cell lines were treated with 5'-Aza (Sigma) to determine whether demethylation could restore RIZ1 expression. Cells were plated and treated with 0,5 and $25 \mu \mathrm{M}$ of $5^{\prime}$-Aza for 3 days, changing the medium containing 5'-Aza every day before extracting the genomic DNA and total RNA.

Chromatin immunoprecipitation (ChIP). The ChIP experiments were performed using an EZ ChIP ${ }^{\text {Tм }}$ Chromatin Immunoprecipitation kit for cell line samples (Millipore, Billerica, MA, USA) according to the manufacturer's instructions. Briefly, the crosslinked chromatin DNA were sonicated into 200-1000 bp fragments and fixed with $1 \%$ formaldehyde. Then immunoprecipitation followed using an anti-DNMT1 
Table I. Primers and annealing temperature of genes and the sequence of siRNA.

\begin{tabular}{|c|c|c|c|}
\hline Gene & Primers $\left(5^{\prime}-3^{\prime}\right)$ & Temperature $\left({ }^{\circ} \mathrm{C}\right)$ & Amplification size (bp) \\
\hline$\beta$-actin & $\begin{array}{l}\text { F: AAAGACCTGTACGCCAACAC } \\
\text { R: GTCATACTCCTGCTTGCTGAT }\end{array}$ & 60 & 220 \\
\hline RIZ1 & $\begin{array}{l}\text { F: GAACACTACTGAGCCTGTGG } \\
\text { R: ACACCAATCCGGGTCTTGTC }\end{array}$ & 62 & 124 \\
\hline HBx & $\begin{array}{l}\text { F: GACGTCCTTTGTCTACGTCC } \\
\text { R: GAACGGCAGATGAAGAAGGG }\end{array}$ & 64 & 97 \\
\hline DNMT1 & $\begin{array}{l}\text { F: CCGAGTTGGTGATGGTGTGTAC } \\
\text { R: AGGTTGATGTCTGCGTGGTAGC }\end{array}$ & 61 & 324 \\
\hline DNMT3A & $\begin{array}{l}\text { F: TATTGATGAGCGCACAAGAGAGC } \\
\text { R: GGGTGTTCCAGGGTAACATTGAG }\end{array}$ & 65 & 110 \\
\hline DNMT3B & $\begin{array}{l}\text { F: GACTTGGTGATTGGCGGAA } \\
\text { R:GGCCCTGTGAGCAGCAGA }\end{array}$ & 64 & 270 \\
\hline RIZ1-Promoter & $\begin{array}{l}\text { F: GCGTTGGTCACTGCTCCTGG } \\
\text { R: CAAGTCCGACCGCACCCTA }\end{array}$ & 60 & 249 \\
\hline miR-152 & $\begin{array}{l}\text { Stem-loop } \\
\text { GTCGTATCCAGTGCAGGGTCCGAGGTATT } \\
\text { CGCACTGGATACGACCCAAGT } \\
\text { F: GTCGTCAGTGCATGACAGAACTT } \\
\text { R: GTGCAGGGTCCGAGGT }\end{array}$ & 58 & 60 \\
\hline U6 & $\begin{array}{l}\text { F: CGCTTCGGCAGCACATATACTA } \\
\text { R: CGCTTCGGCAGCACATATACTA }\end{array}$ & 64 & 90 \\
\hline RIZ1 & $\begin{array}{l}\text { MF: GTGGTGGTTATTGGGCGACGGC } \\
\text { MR: GCTATTTCGCCGACCCCGACG }\end{array}$ & 57 & 225 \\
\hline RIZ1 & $\begin{array}{l}\text { UF: TGGTGGTTATTGGGTGATGGT } \\
\text { UR: ACTATTTCACCAACCCCAAGA }\end{array}$ & 58 & 221 \\
\hline miR-152 mimics & $\begin{array}{l}\text { UCAGUGCAUGACAGAACUUGG } \\
\text { AAGUUCUGUCAUGCACUGAUU }\end{array}$ & & \\
\hline Negative control & $\begin{array}{l}\text { UUCUCCGACGUGUCACGUTT } \\
\text { ACGUGACACGUUCGGAGAATT }\end{array}$ & & \\
\hline
\end{tabular}

antibody and normal mouse $\operatorname{IgG}$ as the negative control. The primers used for the amplification of RIZ1 promoter DNA fragments are listed in Table I.

Statistical analysis. The independent Student's t-test was used to compare the results expressed as mean $\pm \mathrm{SD}$ and Chi-square $\left(\chi^{2}\right)$ test for categorical variables between any two pre-selected groups. A P-value $<0.05$ was considered to indicate a statistically significant difference.

\section{Results}

$H B x$ represses $R I Z 1$ expression in HCC cells. We analyzed the differential expression profiles in L02-HBx and control L02-Vector cells by cDNA microarray analysis in a previous study (11). Of these altered genes, RIZ1, a typical downregulated gene in L02-HBx cells, was selected for further research because of its location on 1 p36 region, which commonly undergoes loss of heterozygosity ( $\mathrm{LOH}$ ) in HCC (15). However, it is unclear whether RIZ1 expression level is related to $\mathrm{HCC}$.

The L02 and SMMC-7721 cells were transfected with the pcDNA4-HBx and pcDNA4 vectors. Results showed that RIZ1 was downregulated in $\mathrm{HBx}$ transfected cells compared with the control cells (vector) both at RNA level and protein level (Fig. 1A). To further verify whether this downregulation of RIZ1 is correlated with HBx expression, we examined the expression level of RIZ1 and HBx in HCC cell lines. The expression of RIZ1 was relatively low in $\mathrm{HBx}$ positive cells MHCC-97H and HepG2.215 compared to HBx negative ones (Fig. 1B). Hence, to some extent, this negative correlation between the expression of RIZ1 and HBx in HCC cell lines confirmed that the RIZ1 expression is related to $\mathrm{HBx}$.

Hypermethylation contributes to the downregulation of RIZ1 induced by HBx. Hypermethylation of the RIZ1 promoter is 


\section{A}

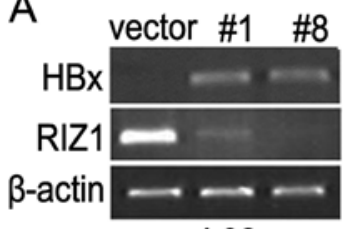

L02

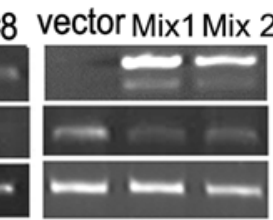

SMMC-7721 vector \#1 \#8 vector Mix $1 \mathrm{Mix} 2$

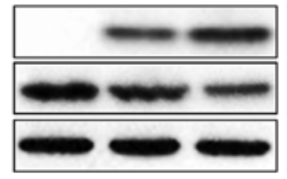

L02

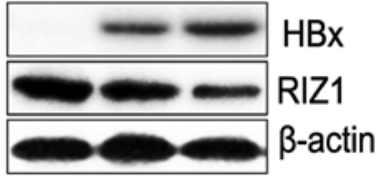

SMMC-7721

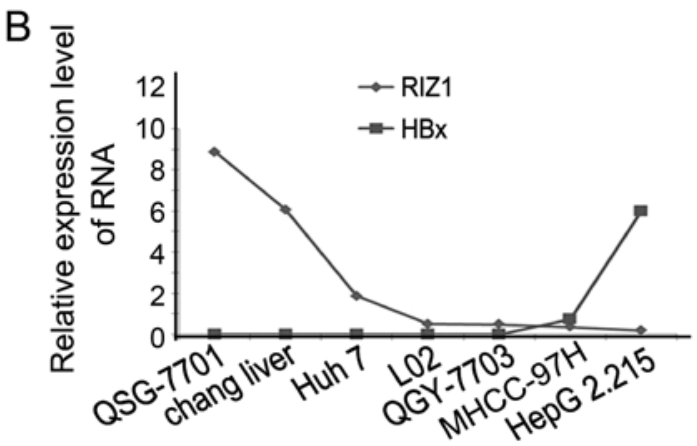

Figure 1. HBx represses RIZ1 expression in HCC cell lines. (A) The expression level of HBx were detected in L02 and SMMC-7721 cells transfected with HBx expression constructs or control vectors in RNA (left lane) and protein level (right lane). SMMC-7721 cells transiently transfected with HBx expression constructs or control vectors and L02 cells stably transfected with HBx expression constructs. The \#1 and \#8 cell lines are the two HBx transfectants (L02-HBx \#1 and L02-HBx \#8). The Mix 1 and Mix 2 cell lines are the two HBx transfected SMMC-7721 mixture cells. $\beta$-actin was used as a loading control. (B) Expression levels of RIZ1 and HBx were examined in the hepatic cell (L02) and the HCC cell lines by RT-PCR. $\beta$-actin was used as a loading control.
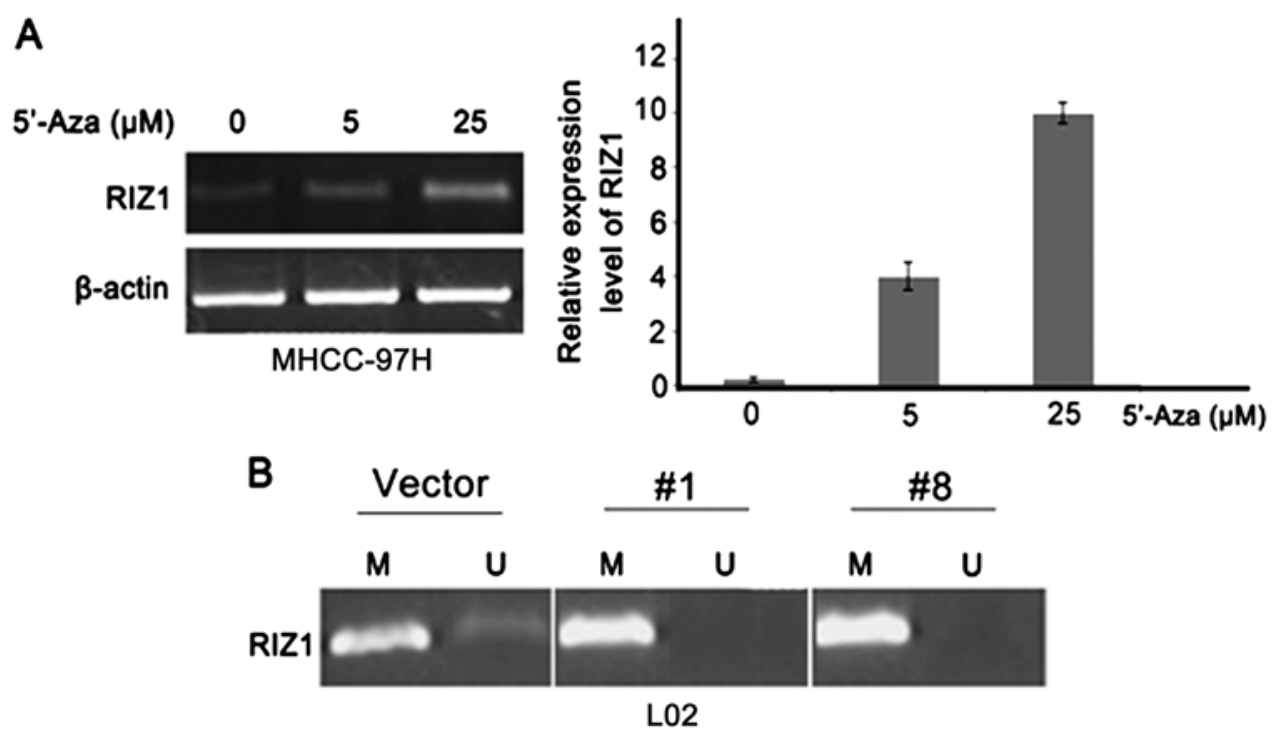

Figure 2. DNA methylation contributes to the decreased expression of RIZ1 in HCC cells. (A) MHCC-97H cells were treated with 0,5 and $25 \mu \mathrm{M}$ of 5'-Aza for 3 days, the expression of RIZ1 was detected by RT-PCR. (B) The methylation status of RIZ1 promoter was analyzed by methylation specific PCR (MSP) in L02 cells stably transfected with HBx (L02-HBx \#1 and L02-HBx \#8) and control constructs. M, methylation specific primer amplification, and U, unmethylation specific amplification.

one of the most frequent epigenetic inactivation events, which lead to silencing of RIZ1 expression in various tumors (21-23). 5'-Aza, an inhibitor of DNMTs, was used to treat the HCC cell lines. After treatment of 5'-Aza, RIZ1 expression level was restored depending on the dose of the drug (Fig. 2A). Next, we investigated whether HBx induces the hypermethylation of RIZ1 promoter by methylation-specific PCR (MSP). The methylation status of RIZ1 promoter region were examined between L02-Vec and L02-HBx 1\# and L02-HBx 8\# cells (Fig. 2B). The results showed that HBx was able to, at least partly, increase the methylation level of RIZ1 promoter in HBx transfected L02 cells.
HBx represses $R I Z 1$ expression through increasing DNMT1 level. As DNA methylation is catalyzed by DNA methyltransferase including DNMT1, DNMT3A and DNMT3B, we aimed to investigate whether the HBx-mediated RIZ1 inactivation induced by hypermethylation is related to DNMTs. In HBx transfected SMMC-7721 cells and L02 cells, DNMT1 were upregulated rather than DNMT3A and DNMT3B. DNMT1 expression were significantly upregulated in SMMC-7721 cells transfected with $\mathrm{HBx}$ in both RNA and protein levels (Fig. 3A). DNMT1 expression was upregulated in L02-HBx 1\# and L02-HBx $8 \#$ cells in protein level, however, in RNA level, DNMT1 was no significant upregulated in these cells (Fig. 3B). 
A

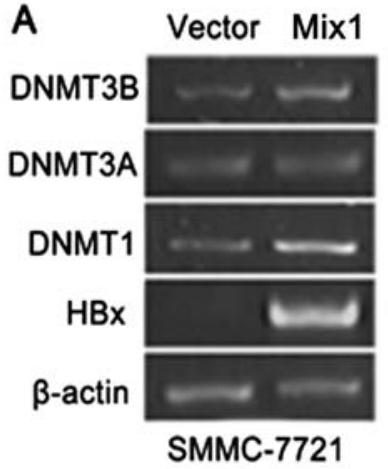

C

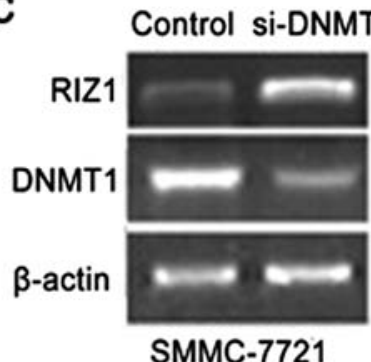

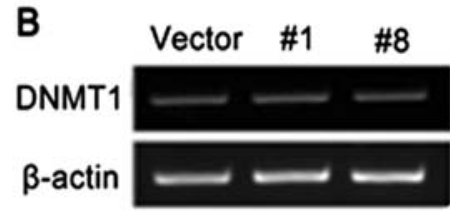

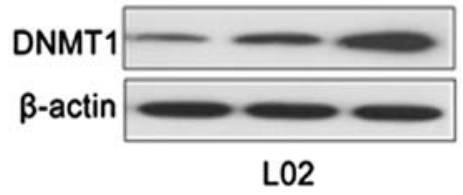

L02

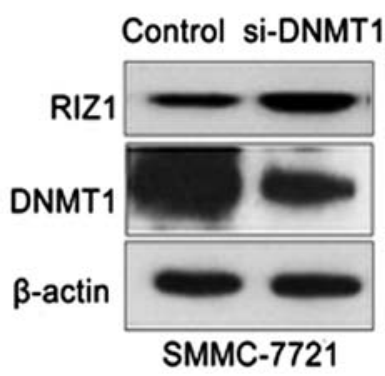

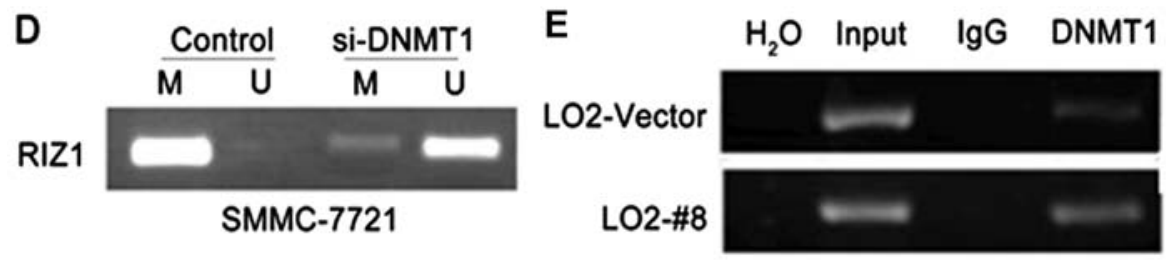

Figure 3. DNMT1 mediates the repression of RIZ1 by HBx. (A) The levels of mRNAs encoding DNMT1, DNMT3A, and DNMT3B were detected by RT-PCR in SMMC-7721 cells transiently transfected with the HBx expression construct or the control vector. $\beta$-actin was used as a loading control. (B) DNMT1 expression levels were detected by RT-PCR (upper) and western blotting (lower) in L02 cells stably transfected with the HBx expression construct or the control vector. (C) RIZ1 and DNMT1 expression levels were detected by RT-PCR and western blotting in SMMC-7721 cells after knockdown of DNMT1 by RNAi (siDNMT1) and control cells. $\beta$-actin was used as a loading control. (D) The methylation status of RIZ1 promoter was analyzed by methylation specific PCR (MSP) in SMMC-7721 cells transiently transfected with DNMT1 RNAi (siDNMT1) and control cells. M showed methylation specific primer amplification while U showed unmethylation specific amplification. (E) ChIP assay was performed in L02-Vector and L02-HBx \#8 cells using a DNMT1 specific antibody, followed by PCR amplification of an individual fragments representing RIZ1 promoter regions. Chromatin (defined as 'Input') and DNA products immunoprecipitated by IgG were used as positive and negative controls, respectively. $\mathrm{H}_{2} \mathrm{O}$ was the blank control.

In order to explore whether DNMT1 is responsible for the expression of RIZ1, we depleted the DNMT1 expression using siRNA in HCC cell lines and observed that the RIZ1 is upregulated after knocking down of DNMT1 (Fig. 3C). Moreover, knockdown of DNMT1 reduced partly the methylation level of RIZ1 promoter (Fig. 3D). ChIP analysis using an antibody against DNMT1 revealed that the binding of DNMT1 to RIZ1 promoter regions is enriched in L02-HBx cells (Fig. 3E), which suggested that DNMT1 mediates the repression of RIZ1 by HBx. Collectively, these data suggested that DNMT1 modulated RIZ1 by directly binding to and silencing RIZ1 gene via promoter hypermethylation in HBx expression cells.

HBx increases DNMT1 level via suppressing miR-152. Next, we investigated how HBx induced DNMT1 expression. It is well known that $\mathrm{HBx}$ can deregulate the expression of cellular miRNAs $(8,24,25)$. Therefore, we examined whether HBx could deregulate a specific candidate miRNA and regulate DNMT1 expression. Several studies previously demonstrated that DNMT1 3'-UTR is partially complementary to miR-152 (26-28) and is a direct target gene of miR-152 in several cancer types (Fig. 4A). In the present study, we found that overexpression of $\mathrm{HBx}$ decreases miR-152 expression (Fig. 4B), while overexpression of miR-152 reduces DNMT1 expression (Fig. 4C).

Downregulation of RIZ1 in tumor tissues correlates to $H B V$-related $H C C$. RIZ1 expression was analyzed by RT-PCR in 26 pairs of HCC cases and immunohistochemistry (IHC) in 68 pairs of cases. Seven representative results are shown in Fig. 5A. Compared to the paired corresponding non-tumor tissues, $70 \%$ of HCC cases showed downregulation of RIZ1 at the protein level (Fig. 5B). Downregulated expression of RIZ1 protein was detected by western blotting in HCC cell lines compared with L02 cells which are immortal hepatic cells (Fig. 5C). HCC cases (65\%) showed a decreased expression of RIZ1 in RNA level (Fig. 5D). Then, HCC patients were divided into sub-groups based on their relative HBx mRNA status. Interestingly, in the clinical cases with high HBx group, the expression of RIZ1 was significantly decreased in tumor tissues compared to non-tumor tissues (Fig. 5E). Collectively, the relationship between HBx and RIZ1 mRNA levels in HCC samples revealed a negative correlation between RIZ1 and HBx expression in HCC patients. 


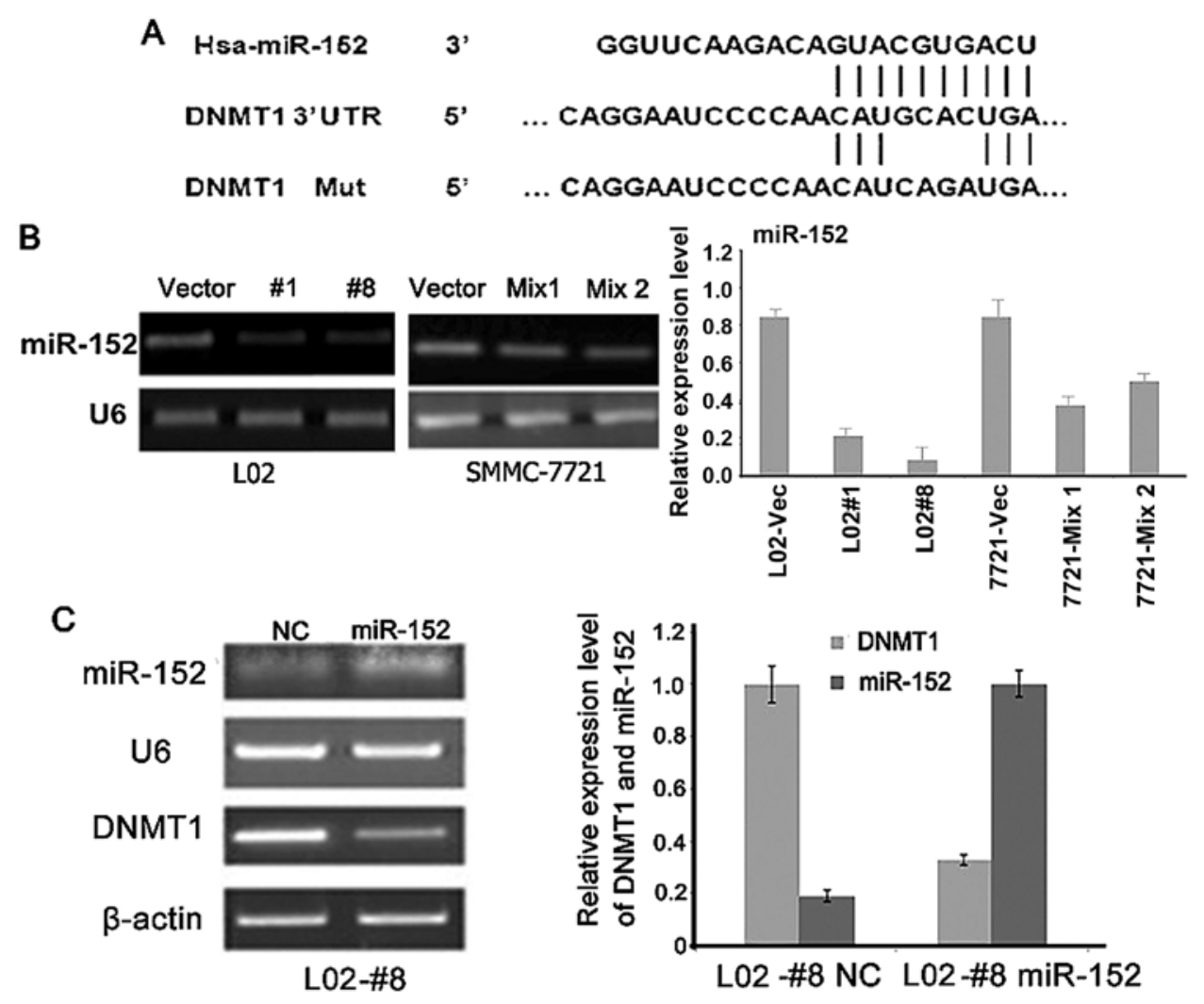

Figure 4. miR-152 is decreased by HBx and involved in HBx-mediated repression of DNMT1. (A) DNMT1 3'-UTR is partially complementary to miR-152. (B) HBx decreased miR-152 expression in cells stably transfected with HBx expression constructs (L02-HBx \#1 and L02-HBx \#8). Lane right show the relative expression level of miR-152 in HBx-transfected cells. (C) RT-PCR and qPCR analysis of miR-152 and DNMT1 expression in L02-HBx and L02-Vector cells after transected with miR-152 minics and control. The bars represent the mean \pm SD of three independent experiments.

\section{Discussion}

HBV is a major risk factor worldwide for developing HCC and contributes to HCC by multiple mechanisms. Among HBV proteins, HBx is highly conserved among the different subtypes of the virus and play a crucial role in hepatocellular carcinogenesis as a multifunctional regulator. Recent studies have shown that HBx was able to influence gene expression involve in various signaling pathways, as well as epigenetic and genetic processes. RIZ (PRDM2), a candidate HCC suppressor gene, is a member of the PR (PRDI-BF1-RIZ homology)-domain-containing zinc finger gene family. The PR-domain-containing RIZ1 product of the RIZ locus, in contrast to the PR-domain-minus product RIZ2, is commonly lost or underexpressed in HCC (15).

RIZ1 has tumor suppressor activity and is frequently loss of its function in many human cancers. Some frameshift mutation, $\mathrm{LOH}$ or promoter methylation is the main cause responsive for inactivation RIZ1 in human gastric cancer $(16,17)$. DNA methylation is a common mechanism for the inactivating of the RIZ1 tumor suppressor gene in human liver and breast cancers (29). YY1 protein binds and cooperates to positive regulation of the RIZ1 promoter in human osteosarcoma cells and tissues (30). Reduced expression of RIZ1 may play an important role in the pathogenesis and/or development of cervical cancer, and is considered to be caused in part by aberrant DNA methylation (31). Epigenetic silencing of RIZ1 gene may play an important role in the early stage human ESCC (32). The expression of RIZ1 genes are associated with meningiomas progression by inhibiting cellular proliferation and arrested the cells in the G2/M phase of the cell cycle (13). Induced expression of RIZ1 in glioma cells increased apoptosis and arrested cells in G2-M phase by increased p53 and caspase- 3 expression and decreased p-IKB $\alpha$ and p-AKT protein levels, suggesting that RIZ1 may stimulate p53-mediated apoptosis and inhibit $\mathrm{p}-\mathrm{IKB} \alpha$ and $\mathrm{p}-\mathrm{AKT}$ signaling pathways (33). In HCC, RIZ1 can induce cell cycle arrest, apoptosis, or both and suppress HCC tumorigenicity in nude mice. The promoter methylation and $\mathrm{H} 3 \mathrm{~K} 9$ modifications together to silence the RIZ1 gene in HCC (18). These studies have focused on the methylation status of RIZ1 and its expression. However, the underlying mechanisms involved in RIZ1 silencing, especially in HBX related HCC, still remain unknown.

In the present study, we found RIZ1 mRNA levels were lower in HBX transfected L02-HBX cells, than in the control. DNA methylation is a common mechanism in inactivating the RIZ1 tumor suppressor gene in human liver and breast cancers (29). The objective of the present study was to investigate the mechanism of decreased expression of RIZ1 induced by HBX in HCC cells. HBx recombinant transfection decreased RIZ1 expression, however, 5'-Aza restored RIZ1 expression in MHCC-97H cell lines. As is known, DNA methylation is catalyzed by DNMTs, it is necessary to investigate the expression level of DNMT1, DNMT3A and DNMT3B in HBx-induced HCC cells. The result showed that the expression of DNMT1 rather than DNMT3A and/or DNMT3B is significant upregulated. Subsequently, DNMT1 siRNA restored RIZ1 expression in SMMC-7721 cells with demethylation of CpG sites in RIZ1 
A

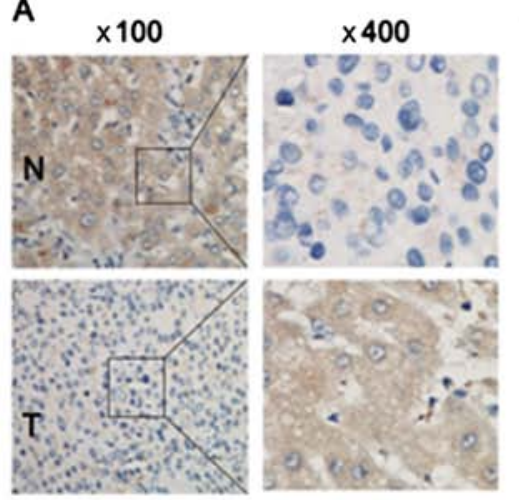

B

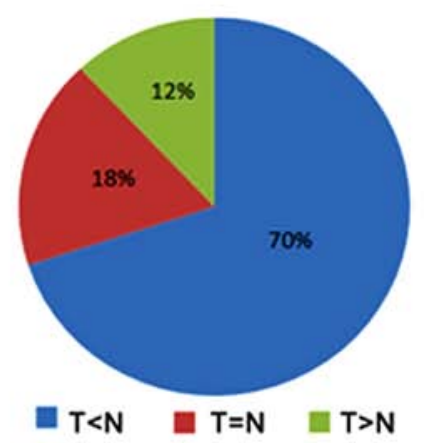

C

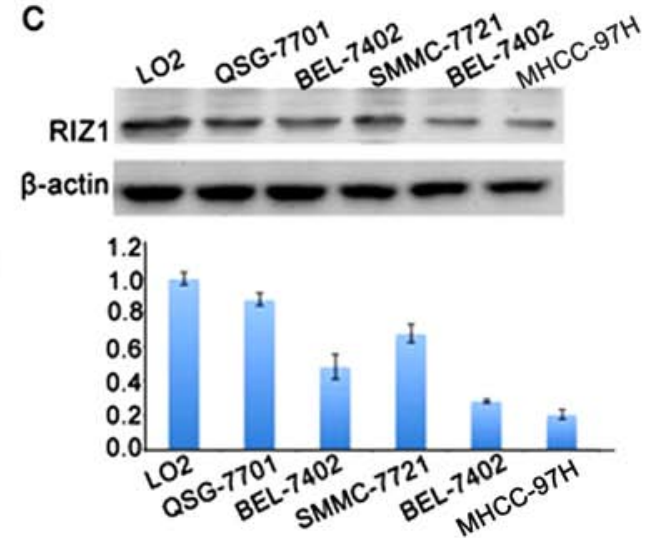

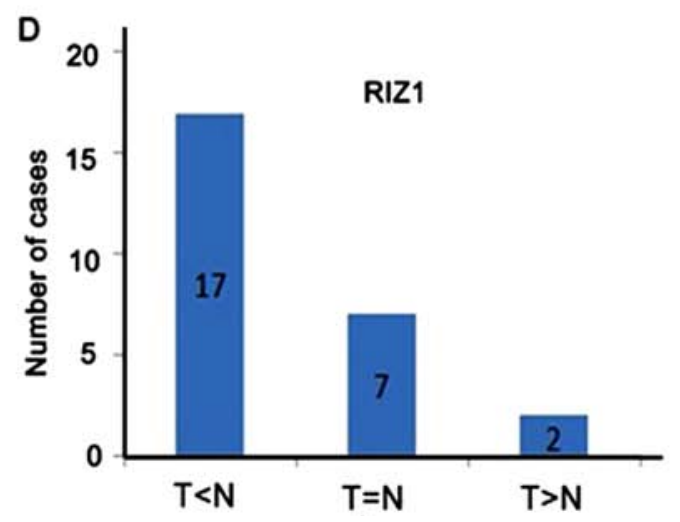

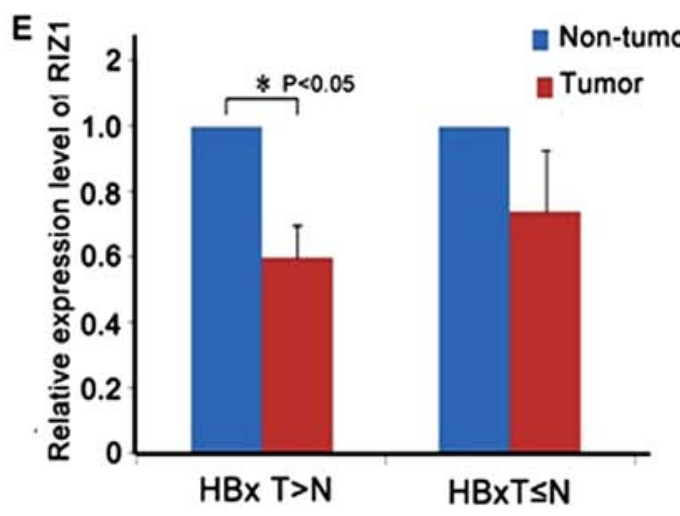

Figure 5. RIZ1 is downregulated in HBV-related HCC. (A and B) Immunohistochemical staining of RIZ1 protein in a representative HCC sample and its matched non-tumor tissue specimen $(\mathrm{n}=64)$. RIZ1 was expressed at lower levels in HCC samples compared to their matched non-tumor tissues. (C) RIZ1 protein expression was detected in $5 \mathrm{HCC}$ cell lines and the immortal normal hepatic cells (L02) by western blotting. (D) Analysis of the relative expression of RIZ1 in the 26 paired HCC and matched non-tumor tissues; 17, 7 and 2 are case numbers. Two-fold was used as the cut-off. (E) The HCC patients are divided into sub-groups based on their relative HBx status as $\mathrm{HBx}(\mathrm{T}>\mathrm{N})$ (cases in which HBx expression was 2-fold higher in the HCC sample than the matched non-tumor tissues) and $\mathrm{HBx}(\mathrm{T} \leq \mathrm{N})$ (cases in which HBx expression was 2-fold lower in the HCC sample than the matched non-tumor tissues). RIZ1 was down-expressed in tumor in the clinical cases where HBx was higher expressed in tumor than non-tumor tissues ( $\mathrm{P}<0.05$, independent Student's t-test).

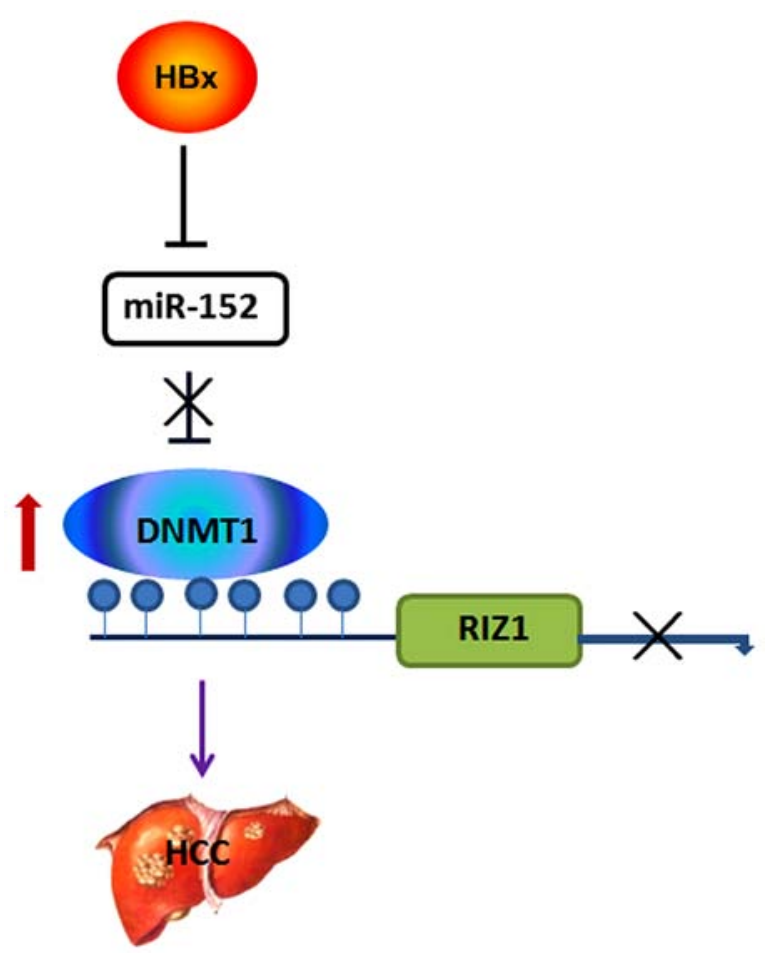

Figure 6. The diagram presents HBx upregulated DNMT1 to suppress RIZ1 expression in HCC cells. HBx activiates DNMT1 expression, then DNMT1 suppresses RIZ1 expression by DNA methylation. $\rightarrow$, activation; -----1, inhibition. promoter region. ChIP results showed DNMT1 protein can binds to the RIZ1 promoter in HCC cells transfected with HBX recombinant. This is the first report that DNMT1 is involved in epigenetic inactivation of RIZ1 in tumor cells.

Accumulating evidence implied that $\mathrm{HBx}$ can deregulate a set of miRNAs (8). Large-scale miRNA expression profiling of human cancers have revealed that miRNA deregulation is frequently associated with a variety of tumors including human HCC $(9,11,34,35)$. These findings highlight the role of miRNA in $\mathrm{HBV}$ relative HCC carcinogenesis. Several studies have previously demonstrated that DNMT1 is a direct target gene of miR-152 (27,28). Thus, we present a hypothesis where miR-152 may contribute to the HBx-mediated upregulation of DNMT1. We first found that miR-152 levels were downregulated in HBx stably transfected L02 cells. Furthermore, miR-152 minic inhibited DNMT1 in L02-HBx \#8 cells. Enhanced miR-152 was able to abolish the HBx-mediated upregulation of DNMT1 in L02-HBx cells. This finding suggests that HBx downregulates RIZ1 expression in hepatoma cells by enhancing partly the expression of DNMT1, via decreased miR-152. Upregulation of DNMT1 mediated by HBx might be one of mechanisms suppressing RIZ1 expression in HCC. The present study also showed that the expression of RIZ1 was downregulated in HCC tissues and cell lines. In HCC cases, the decreased expression rates of RIZ1 were 70\%. A significant negative relationship between the expression of HBx and 
the expression of RIZ1 was observed in HCC patients and HCC cell lines.

In summary (Fig. 6), our results reveled that the transfection of HBX can reduce miR-152 and upregulate the expression of DNMT1. DNMT1 regulates the expression of RIZ1, partly, by modulating the methylation status of RIZ1 promoter. We are the first to report that HBx downregulates RIZ1 expression, at least partly, associated with miR-152.

\section{Acknowledgements}

This work was supported by the National Natural Science Foundation of China (no. 91229107, no. 81472548 and no. 81672414), Innovative Scientific Research Projects for College Graduates of Jiangsu Province (no. 3231005701). We thank Professor Xinyuan Guan, University of Hong Kong, for providing the HBx construct.

\section{References}

1. Llovet JM, Burroughs A and Bruix J: Hepatocellular carcinoma. Lancet 362: 1907-1917, 2003.

2. Beasley RP, Hwang LY, Lin CC and Chien CS: Hepatocellular carcinoma and hepatitis B virus. A prospective study of 22707 men in Taiwan. Lancet 2: 1129-1133, 1981.

3. Wang Y, Cui F, Lv Y, Li C, Xu X, Deng C, Wang D, Sun Y, Hu G, Lang Z, et al: HBsAg and HBx knocked into the p21 locus causes hepatocellular carcinoma in mice. Hepatology 39: 318-324, 2004

4. Soejima K, Fang W and Rollins BJ: DNA methyltransferase $3 \mathrm{~b}$ contributes to oncogenic transformation induced by SV40T antigen and activated Ras. Oncogene 22: 4723-4733, 2003.

5. Park IY, Sohn BH, Yu E, Suh DJ, Chung YH, Lee JH, Surzycki SJ and Lee YI: Aberrant epigenetic modifications in hepatocarcinogenesis induced by hepatitis B virus X protein. Gastroenterology 132: 1476-1494, 2007.

6. Tsai CN, Tsai CL, Tse KP, Chang HY and Chang YS: The Epstein-Barr virus oncogene product, latent membrane protein 1 , induces the downregulation of E-cadherin gene expression via activation of DNA methyltransferases. Proc Natl Acad Sci USA 99: 10084-10089, 2002.

7. Qiu X,Zhang L, Lu S, Song Y,Lao Y,Hu J and Fan H: Upregulation of DNMT1 mediated by HBx suppresses RASSF1A expression independent of DNA methylation. Oncol Rep 31: 202-208, 2014.

8. Wang Y, Lu Y, Toh ST, Sung WK, Tan P, Chow P, Chung AY, Jooi LL and Lee CG: Lethal-7 is down-regulated by the hepatitis $\mathrm{B}$ virus $\mathrm{x}$ protein and targets signal transducer and activator of transcription 3. J Hepatol 53: 57-66, 2010.

9. Murakami Y, Yasuda T, Saigo K, Urashima T, Toyoda H, Okanoue $\mathrm{T}$ and Shimotohno $\mathrm{K}$ : Comprehensive analysis of microRNA expression patterns in hepatocellular carcinoma and non-tumorous tissues. Oncogene 25: 2537-2545, 2006.

10. Lin L, Yin X, Hu X, Wang Q and Zheng L: The impact of hepatitis B virus $x$ protein and microRNAs in hepatocellular carcinoma: A comprehensive analysis. Tumour Biol 35: 11695-11700, 2014.

11. Qiu X, Dong S, Qiao F, Lu S, Song Y, Lao Y, Li Y, Zeng T, $\mathrm{Hu}$ J, Zhang L, et al: HBx-mediated miR-21 upregulation represses tumor-suppressor function of PDCD4 in hepatocellular carcinoma. Oncogene 32: 3296-3305, 2013.

12. Buyse IM, Shao G and Huang S: The retinoblastoma protein binds to RIZ, a zinc-finger protein that shares an epitope with the adenovirus E1A protein. Proc Natl Acad Sci USA 92: 4467-4471, 1995.

13. Liu ZY, Wang JY, Liu HH, Ma XM, Wang CL, Zhang XP, Tao YQ, Lu YC, Liao JC and Hu GH: Retinoblastoma proteininteracting zinc-finger gene 1 (RIZ1) dysregulation in human malignant meningiomas. Oncogene 32: 1216-1222, 2013.

14. Suzuki M, Shigematsu H, Shivapurkar N, Reddy J, Miyajima K, Takahashi T, Gazdar AF and Frenkel EP: Methylation of apoptosis related genes in the pathogenesis and prognosis of prostate cancer. Cancer Lett 242: 222-230, 2006.

15. Fang W, Piao Z, Simon D, Sheu JC and Huang S: Mapping of a minimal deleted region in human hepatocellular carcinoma to 1p36.13-p36.23 and mutational analysis of the RIZ (PRDM2) gene localized to the region. Genes Chromosomes Cancer 28: 269-275, 2000.
16. Tokumaru Y, Nomoto S, Jerónimo C, Henrique R, Harden S, Trink B and Sidransky D: Biallelic inactivation of the RIZ1 gene in human gastric cancer. Oncogene 22: 6954-6958, 2003.

17. Oshimo Y, Oue N, Mitani Y, Nakayama H, Kitadai Y, Yoshida K, Chayama $\mathrm{K}$ and Yasui W: Frequent epigenetic inactivation of RIZ1 by promoter hypermethylation in human gastric carcinoma. Int J Cancer 110: 212-218, 2004.

18. Zhang C, Li H, Wang Y, Liu W, Zhang Q, Zhang T, Zhang X, Han B and Zhou G: Epigenetic inactivation of the tumor suppressor gene RIZ1 in hepatocellular carcinoma involves both DNA methylation and histone modifications. J Hepatol 53: 889-895, 2010.

19. Nishida N, Nagasaka T, Nishimura T, Ikai I, Boland CR and Goel A: Aberrant methylation of multiple tumor suppressor genes in aging liver, chronic hepatitis, and hepatocellular carcinoma. Hepatology 47: 908-918, 2008.

20. Fan H, Liu D, Qiu X, Qiao F, Wu Q, Su X, Zhang F, Song Y, Zhao Z and Xie W: A functional polymorphism in the DNA methyltransferase-3A promoter modifies the susceptibility in gastric cancer but not in esophageal carcinoma. BMC Med 8: $12,2010$.

21. Chappell G, Kutanzi K, Uehara T, Tryndyak V, Hong HH, Hoenerhoff M, Beland FA, Rusyn I and Pogribny IP: Genetic and epigenetic changes in fibrosis-associated hepatocarcinogenesis in mice. Int J Cancer 134: 2778-2788, 2014.

22. Hutajulu SH, Indrasari SR, Indrawati LP, Harijadi A, Duin S, Haryana SM, Steenbergen RD, Greijer AE and Middeldorp JM: Epigenetic markers for early detection of nasopharyngeal carcinoma in a high risk population. Mol Cancer 10: 48, 2011.

23. Mori N, Yoshinaga K, Tomita K, Ohwashi M, Kondoh T, Shimura H, Wang YH, Shiseki M, Okada $M$ and Motoji T: Aberrant methylation of the RIZ1 gene in myelodysplastic syndrome and acute myeloid leukemia. Leuk Res 35: 516-521, 2011.

24. Zhang X, Liu S, Hu T, Liu S, He Y and Sun S: Up-regulated microRNA-143 transcribed by nuclear factor kappa B enhances hepatocarcinoma metastasis by repressing fibronectin expression. Hepatology 50: 490-499, 2009

25. Kong G, Zhang J, Zhang S, Shan C, Ye L and Zhang X: Upregulated microRNA-29a by hepatitis B virus X protein enhances hepatoma cell migration by targeting PTEN in cell culture model. PLoS One 6: e19518, 2011.

26. Xiang Y, Ma N, Wang D, Zhang Y, Zhou J, Wu G, Zhao R, Huang H, Wang X, Qiao Y, et al: MiR-152 and miR-185 co-contribute to ovarian cancer cells cisplatin sensitivity by targeting DNMT1 directly: A novel epigenetic therapy independent of decitabine. Oncogene 33: 378-386, 2014.

27. Ji W, Yang L, Yuan J, Yang L, Zhang M, Qi D, Duan X, Xuan A, Zhang W, Lu J, et al: MicroRNA-152 targets DNA methyltransferase 1 in NiS-transformed cells via a feedback mechanism. Carcinogenesis 34: 446-453, 2013.

28. Huang J, Wang Y, Guo Y and Sun S: Down-regulated microRNA-152 induces aberrant DNA methylation in hepatitis B virus-related hepatocellular carcinoma by targeting DNA methyltransferase 1. Hepatology 52: 60-70, 2010.

29. Du Y, Carling T, Fang W, Piao Z, Sheu JC and Huang S: Hypermethylation in human cancers of the RIZ1 tumor suppressor gene, a member of a histone/protein methyltransferase superfamily. Cancer Res 61: 8094-8099, 2001.

30. Abbondanza C, de Nigris F, De Rosa C, Rossiello R, Puca GA and Napoli C: Silencing of YY1 downregulates RIZ1 promoter in human osteosarcoma. Oncol Res 17: 33-41, 2008.

31. Cheng HY, Gao Y and Lou G: DNA methylation of the RIZ1 tumor suppressor gene plays an important role in the tumorigenesis of cervical cancer. Eur J Med Res 15: 20-24, 2010.

32. Dong SW, Zhang P, Liu YM, Cui YT, Wang S, Liang SJ, He Z, Sun P and Wang YG: Study on RIZ1 gene promoter methylation status in human esophageal squamous cell carcinoma. World $\mathbf{J}$ Gastroenterol 18: 576-582, 2012.

33. Zhang C, Zhu Q, He H, Jiang L, Qiang Q, Hu L, Hu G, Jiang Y, Ding X and Lu Y: RIZ1: A potential tumor suppressor in glioma. BMC Cancer 15: 990, 2015.

34. Varnholt H, Drebber U, Schulze F, Wedemeyer I, Schirmacher P, Dienes HP and Odenthal M: MicroRNA gene expression profile of hepatitis C virus-associated hepatocellular carcinoma. Hepatology 47: 1223-1232, 2008.

35. Ladeiro Y, Couchy G, Balabaud C, Bioulac-Sage P, Pelletier L, Rebouissou S and Zucman-Rossi J: MicroRNA profiling in hepatocellular tumors is associated with clinical features and oncogene/tumor suppressor gene mutations. Hepatology 47: 1955-1963, 2008 